\title{
UNIVERSITYOF
}

FORWARD

THINKING

WESTMINSTER用

WestminsterResearch

http://www.westminster.ac.uk/westminsterresearch

Compact Inkjet-Printed Broadband Filtennas with Triple

Bandnotch

Ahmad, W. and Budimir, D.

This is a copy of a paper presented at the 46th European Microwave Week (EuMW2016) Conference, 4th - 7th October, 2016.

The WestminsterResearch online digital archive at the University of Westminster aims to make the research output of the University available to a wider audience. Copyright and Moral Rights remain with the authors and/or copyright owners.

Whilst further distribution of specific materials from within this archive is forbidden, you may freely distribute the URL of WestminsterResearch: ((http://westminsterresearch.wmin.ac.uk/).

In case of abuse or copyright appearing without permission e-mail repository@westminster.ac.uk 


\section{Compact Inkjet-Printed Broadband Filtennas with Triple Bandnotch}

\author{
Waqas Ahmad and Djuradj Budimir \\ Wireless Communications Research Group \\ University of Westminster \\ London, UK \\ waqas.ahmad@my.westminster.ac.uk and \\ d.budimir@westminster.ac.uk
}

\author{
Cedo Zlebic \\ Faculty of Technical Sciences \\ University of Novi Sad \\ Novi Sad, Serbia
}

\begin{abstract}
Presented in this paper are the layout and results of a compact inkjet-printed filtenna which is operational at a broadband frequency range, which includes the S-band, ISM and UWB frequencies. Alongside, the filtenna is able to reject the unwanted and interfering WiMAX 3.5 GHz, WLAN $5.8 \mathrm{GHz}$ and ITU service $8.2 \mathrm{GHz}$ signal bands. The filtenna was simulated, printed using silver nanoparticle ink on flexible Kapton substrate and then measured. The achieved simulation and measurement results agree reasonably well against each other. Measured passband of the filtenna is $1.6-10.85 \mathrm{GHz}$ and triple bandnotch, measured at an average value of $1.87 \mathrm{~dB}$, are present at the unwanted bands. The current distributions within the passband region and the bandnotch have also been provided. Obtained radiation patterns show bidirectional patterns in the E-plane and omnidirectional patterns in the H-plane. Additionally, the gain and efficiency of the filtenna have also been presented; with the average values standing at $3.36 \mathrm{dBi}$ and $89.8 \%$ respectively for the passband region and having an average of $-1.0 \mathrm{dBi}$ and 21.3 $\%$ respectively for the triple bandnotch.
\end{abstract}

Keywords—inkjet printing; inkjet antennas; filtennas; uwb; ism band; s-band; broadband; bandnotch; flexible antennas.

\section{INTRODUCTION}

Inkjet printing offers several advantages such as low costs, decrease in waste materials and faster fabrication times. Hence, various inkjet-printed antennas have been published. Some have been intended for sensor integration, such as papermounted temperature and gas sensors; others have been proposed for RFID integration, such as RFID tag readers. Yet little has been achieved in using inkjet printing for broadband filtennas; except in [1]-[4]. But these works still do not satisfy all specifications, such as rejecting unwanted bands and compact size. Inkjet-printed filtennas inside wireless systems should be robust and conformal. Hence, [1]-[3] have been printed on paper-based substrates. Although paper-based substrates are flexible and low-cost, their high dielectric loss factor of 0.07 degrades the efficiency [4] and their relatively low tensile strength leads to discontinuities when they are bent.

Within the broad operational band of the proposed filtenna, i.e. $1.6-10.85 \mathrm{GHz}$, the frequency range of $3.1-10.6 \mathrm{GHz}$ is reserved for unlicensed commercial UWB [5]. This range is overlapped with various other wireless services whose power levels are much higher than the maximum limited within the UWB [5]; such as 3.5 GHz WiMAX, 5.8 GHz WLAN and 8.2 $\mathrm{GHz}$ ITU satellite service bands. These interfere with the main signals; causing loss of sensitivity and signal distortion. Therefore, filtering is required in order to best use the whole operational bandwidth of the filtenna. An effective and possible approach is to apply bandnotch at the frequencies which have to be rejected.

In this paper, the layout of an inkjet-printed broadband filtenna, its fabrication and its testing is presented. The filtenna is printed on flexible Kapton substrate; which is conformal and has a lower dielectric loss factor of 0.0021 [6]. The filtenna has a coplanar waveguide feed design which decreases the printing costs due to being single-layer. The filtenna is operational over a broad range; covering the $2 \mathrm{GHz}$ S-band, $2.45 \mathrm{GHz}$ ISM band and the 3.1-10.6 GHz UWB. It is more compact than the broadband inkjet designs which have been proposed in [1] by $90.6 \%$, [2] by $66.5 \%$, [3] by $55 \%$ and from [4] by $11.7 \%$.

\section{PROPOSED INKJET-PRINTED FILTENNA}

\section{A. Layout of Inkjet-Printed Filtenna}

The final geometry of the filtenna is provided in Fig. 1 and is based on the work in [7]. It measures to a total compact size of $33 \mathrm{~mm} \times 47.2 \mathrm{~mm}$ which equals to $0.35 \lambda_{\mathrm{g}} \times 0.51 \lambda_{\mathrm{g}}$; where $\lambda_{\mathrm{g}}$ is the guided wavelength at $3.1 \mathrm{GHz}$. The filtenna is symmetrical with respect its longitudinal direction. It is designed to have a passband of $1.6-10.6 \mathrm{GHz}$ with a mid-band frequency of $6.1 \mathrm{GHz}$. The middle conductor, i.e. the radiating element, was designed with a long oval shape. Due to the steady change in such a shape with a finite ground plane, there is a smooth transition from one resonant mode to another and, hence, a broadband impedance bandwidth is easily obtained.

To reject the interfering signals, slots and slits which produce a filtering effect, i.e. bandnotch, are incorporated within the radiating patch. The two slits next to both edges of the radiating element are $\lambda_{\mathrm{g}} / 4$ long at $3.5 \mathrm{GHz}$. In order to reject $5.8 \mathrm{GHz}$ and $8.2 \mathrm{GHz}$ bands, two slots for each frequency are cut out. The two slots for $5.8 \mathrm{GHz}$ are positioned on either side of the symmetry plane at a distance of $2.2 \mathrm{~mm}$ from the middle. The two $8.2 \mathrm{GHz}$ slots placed within the symmetry plane at a distance of $11.5 \mathrm{~mm}$ from each other. A 
splitting gap of $0.2 \mathrm{~mm}$ is present in the four slots, from where the current is able to flow in the inner sides of the slots. The four slots measure $\lambda_{\mathrm{g}} / 2$ at their respective bandnotch frequency.

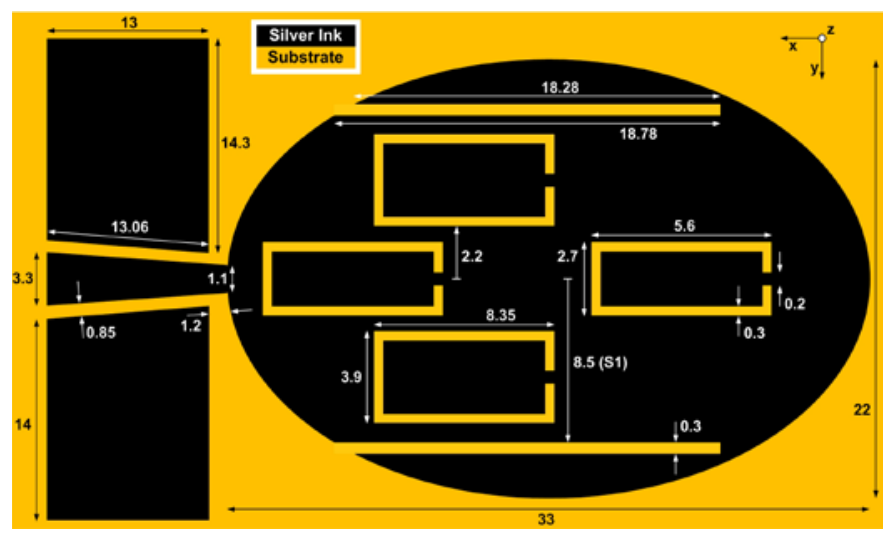

Fig. 1. Geometry (in mm) of inkjet-printed filtenna.

\section{B. Fabrication Process using Inkjet Printing Technology}

Fabrication of the filtenna is done using inkjet printing technology. For the metallisation of the radiating element, the silver nanoparticle ink Novacentrix JS-B80HV [8] is used. For printing the filtenna using the ink, the inkjet printer Dimatix Materials Printer DMP-3000 [9] is used. The printer is set to a drop spacing of $25 \mu \mathrm{m}$ to allow the droplets of ink to adequately overlap one another. The amplitude of the driving waveform is $25 \mathrm{~V}$ and the printing frequency is set to $2 \mathrm{kHz}$. The ink cartridges are laid in a horizontal formation and have a $10 \mathrm{pL}$ nozzle volume. Once printing is completed, the filtenna is sintered and cured in a sintering furnace at a curing temperature of $240^{\circ} \mathrm{C}$ for 45 minutes. This ensures the rough printed lines of ink to form continuous electrically conductive transmission lines, providing a good channel for the flow of current. Since the fabrication involves ink droplets being deposited on a substrate, the method and settings are important and affect the performance of the filtenna. A photograph of the final inkjet-printed product is shown in Fig. 2 (b).

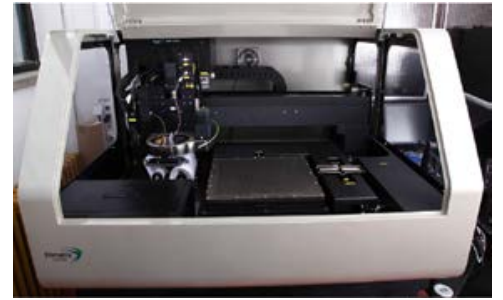

(a)

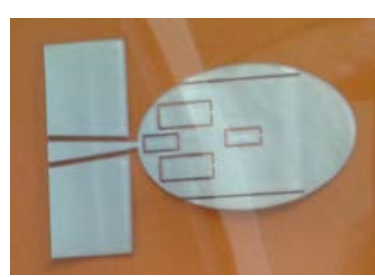

(b)
Fig. 2. Photographs of the (a) inkjet Dimatix Materials Printer DMP-3000 and (b) inkjet-printed filtenna.

\section{RESULTS}

The proposed filtenna was simulated using the commercial electromagnetic software CST Microwave Studio. The Kapton substrate has a dielectric permittivity of 3.4 and a thickness of $50 \mu \mathrm{m}$. A high-frequency system was used to measure the fabricated/printed filtenna. The system comprised of Cascade Microtech PM5 RF and coplanar APC50-GSG-250 probe stations and Agilent N5230A PNA-L and E8361A PNA network analysers. The measuring system was calibrated using compatible impedance characterization substrate using standard Short Open Load calibration method.

\section{A. S-parameters}

The return loss of the filtenna is shown in Fig. 3. Simulation shows a full bandpass response at a return loss of more than $10 \mathrm{~dB}$ from $1.45-10.32 \mathrm{GHz}$. Within this passband, triple bandnotch at $3.5 \mathrm{GHz}, 5.78 \mathrm{GHz}$ and $7.95 \mathrm{GHz}$ are present with a return loss of $0.82 \mathrm{~dB}, 0.87 \mathrm{~dB}$ and $2.11 \mathrm{~dB}$ respectively. Measured results reasonably agree with the simulated results. The measured passband is from 1.6-10.85 $\mathrm{GHz}$. The triple bandnotch are introduced at $3.55 \mathrm{GHz}$ (at 1.8 $\mathrm{dB}), 5.65 \mathrm{GHz}$ (at $1.5 \mathrm{~dB}$ ) and $8.16 \mathrm{GHz}$ (at $2.3 \mathrm{~dB}$ ). The minor $\pm 43.33 \mathrm{MHz}$ frequency shift between the simulated and the measured values of the triple bandnotch is due to the fabrication discrepancies and the reduced return loss is due to the low conductivity of the ink. Hence, these slight differences may be ignored and can be fixed in a later fabrication.

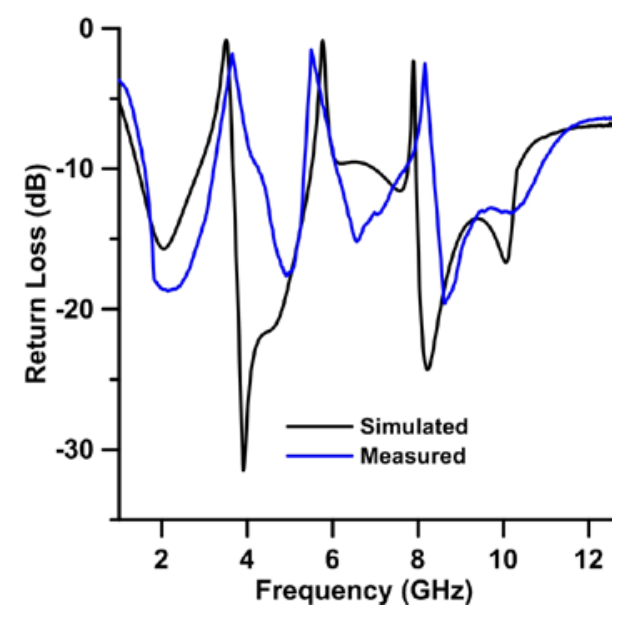

Fig. 3. Return loss of the inkjet-printed filtenna.

\section{B. Parametric Study of Position of $3.5 \mathrm{GHz}$ Bandnotch Slits}

A parametric study was carried out so as to see the effects on the $3.5 \mathrm{GHz}$ bandnotch rejection when the position of its slits was altered. It is expected that the nearer to the base of the oval shape they are placed (nearer the feedline), the more the return loss rejection, i.e. an increase in VSWR. To verify this, the position of the $3.5 \mathrm{GHz}$ slits was changed by using different values for the distance S1 (as seen in Fig. 1) and the structure simulated. The results are presented in Fig. 4 and, for clarity purposes, do not present the return loss but the VSWR within a limited frequency range. Firstly, the slits were moved $2 \mathrm{~mm}$ closer and secondly, a further $2 \mathrm{~mm}$. As projected, the results show an increase in rejection. The $3.5 \mathrm{GHz}$ bandnotch in the final design has a VSWR of 21.2. When the slits are 6.5 
$\mathrm{mm}$ from the middle, the VSWR rises to $46\left(\mathrm{~S}_{11}=0.38 \mathrm{~dB}\right)$ and at $4.5 \mathrm{~mm}$, the VSWR is increased considerably to 107 $\left(\mathrm{S}_{11}=0.16 \mathrm{~dB}\right)$. Both positions show a minor frequency shift from the final design; averaging at $\pm 15 \mathrm{MHz}( \pm 0.42 \%)$.

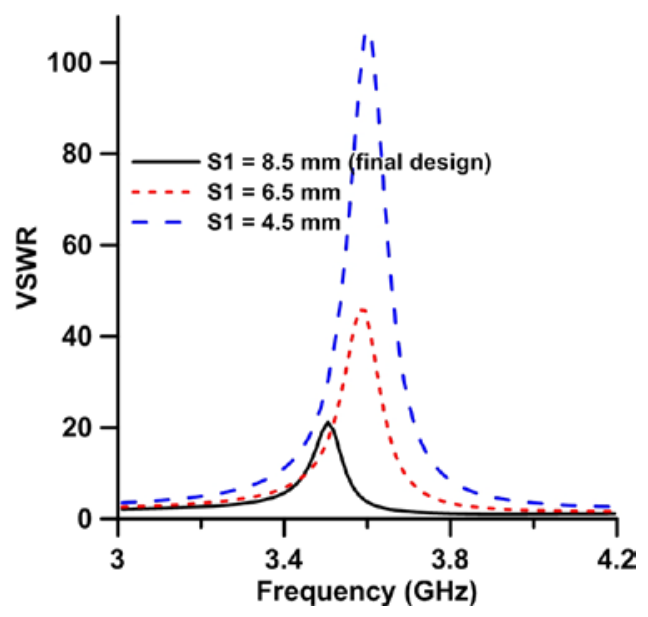

Fig. 4. VSWR of filtenna with varying locations of $3.5 \mathrm{GHz}$ bandnotch slits.

\section{Distribution of Surface Currents}

So as to explain the effects of the slits and slots even further and how the bandnotch are obtained, the current distributions at the three bandnotch frequencies and one bandpass frequency were simulated and are given in Fig. 5. At $4 \mathrm{GHz}$ passband frequency, the scattering of the surface current is nearly spread out over the structure. But, at the bandnotch frequencies, much stronger current distributions are focused on the boundaries of the slits and the slots. Furthermore, a close observation reveals that the directions of the currents along the outer and inner edges of both the slits and slots are opposite to one another. Thus, the currents are cancelled by one another, the filtenna does not radiate and narrow stopband (bandnotch) are obtained.

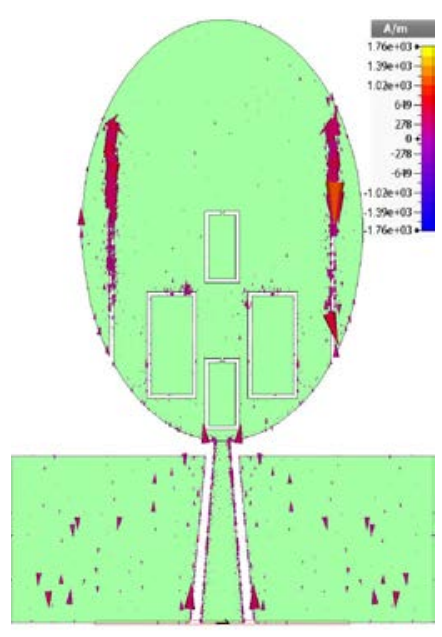

(a)

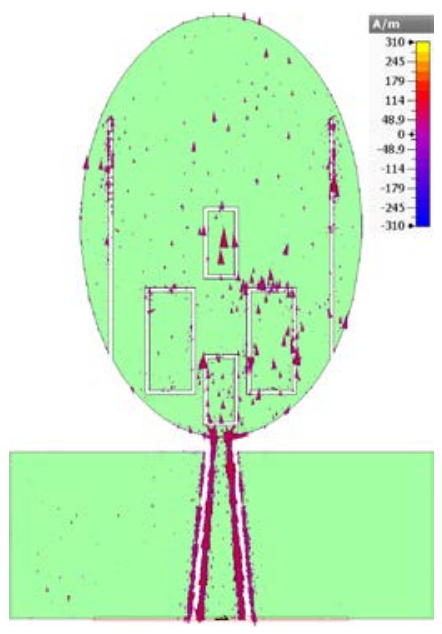

(b)

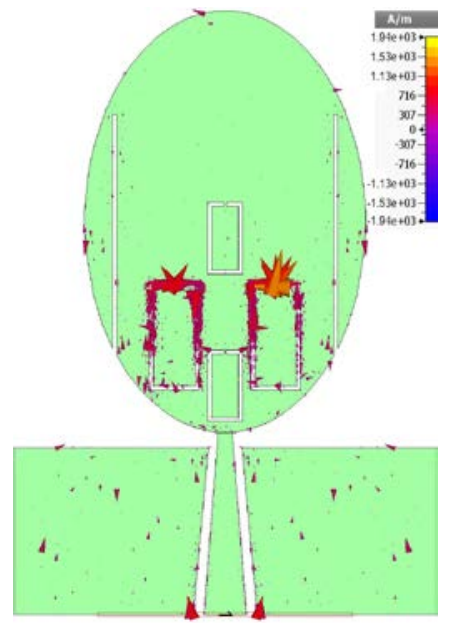

(c)

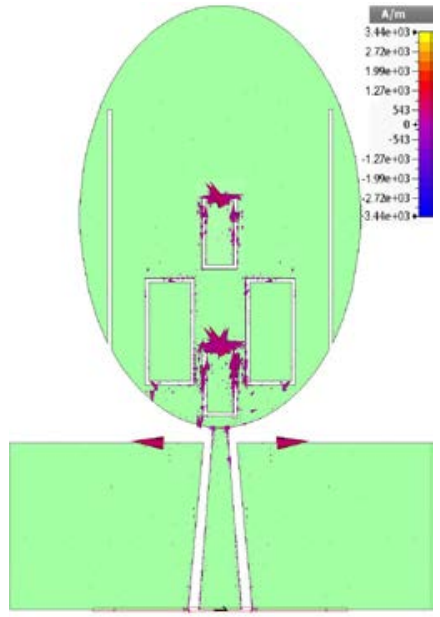

(d)
Fig. 5. Distribution of surface current at (a) $3.5 \mathrm{GHz}$, (b) $4 \mathrm{GHz}$, (c) 5.78 GHz and (d) $7.95 \mathrm{GHz}$.

\section{Radiation Patterns, Gain and Efficiency}

The radiation patterns of the filtenna in the E-plane and the H-plane were obtained at a lower frequency of $4.25 \mathrm{GHz}$ and at a higher frequency of $8.25 \mathrm{GHz}$. The acquired results are shown in Fig. 6. At both frequencies, bidirectional patterns in the E-plane and omnidirectional patterns in the H-plane can be seen. Although stable at $4.25 \mathrm{GHz}$, but as can be observed, at the higher $8.25 \mathrm{GHz}$ frequency, E-plane starts to distort a little.
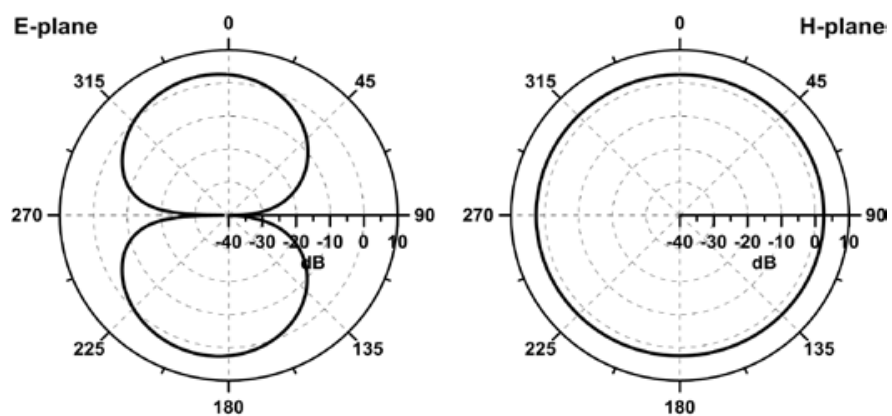

(a)
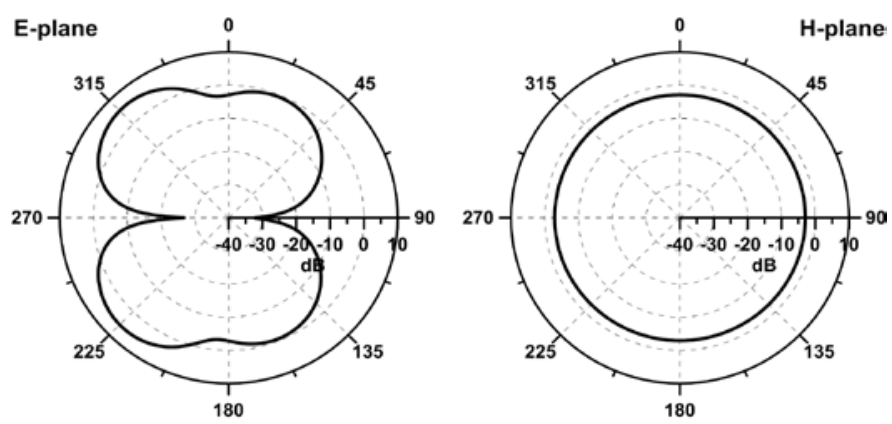

(b)

Fig. 6. Radiation patterns of the filtenna at (a) $4.25 \mathrm{GHz}$ and (b) $8.25 \mathrm{GHz}$. 
Additionally, a comparison of the radiation patterns at the bandnotch frequency of $3.5 \mathrm{GHz}$ and the passband frequency of $4 \mathrm{GHz}$ has been done and is given in Fig. 7. At $4 \mathrm{GHz}$, stable bidirectional pattern in the E-plane and omnidirectional pattern in the H-plane can be seen. However, at $3.5 \mathrm{GHz}$, due to bandnotch suppression, rough bidirectional pattern in the Eplane is seen. Moreover, the magnitude of the patterns at the bandnotch frequency has been significantly reduced in both planes as compared to the passband frequency.
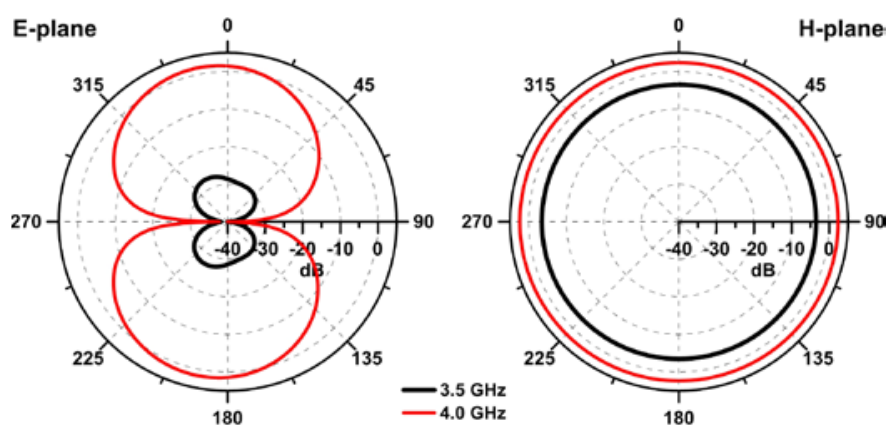

Fig. 7. Comparison of radiation patterns at $3.5 \mathrm{GHz}$ bandnotch frequency (thick line) and $4 \mathrm{GHz}$ passband frequency (thin line).

The simulated gain and efficiency of the filtenna are shown in Fig. 8. The average gain is $3.4 \mathrm{dBi}$ and the average efficiency $90 \%$; except at the triple bandnotch: where, the gain reduces to an average of $-1.0 \mathrm{dBi}$. Also, the efficiency falls to less than $22 \%$. The variance within the gain across the wide passband is within $5 \mathrm{dBi}$. The decline in the gain and efficiency further demonstrates the rejection capabilities of the filtenna.

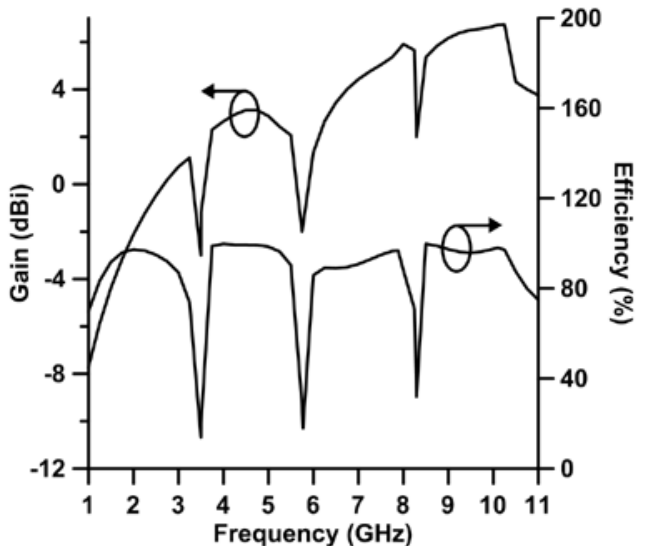

Fig. 8. Gain and efficiency of inkjet-printed filtenna.

\section{CONCLUSION}

Here, a broadband filtenna, realised using inkjet printing of silver nanoparticle ink on flexible Kapton substrate, has been demonstrated. The design and the printing process of the filtenna have been provided. The filtenna has been integrated with slits and slots which act as resonators producing bandnotch at unwanted bands. Simulation and measurement results of the filtenna have been provided and agree well with each other. Results show that a broadband range for the filtenna's passband has been obtained, except at the unwanted $3.5 \mathrm{GHz}$ WiMAX, 5.8 GHz WLAN and 8.2 GHz ITU bands, where sharp triple bandnotch have been introduced. Similar trend, i.e. drop in values, has also been observed in the gain and efficiency.

\section{ACKNOWLEDGMENT}

The fabrication facilities in this work were supported in part by the Ministry of Education, Science and Technological Development of Serbia under grant TR 32016.

\section{REFERENCES}

[1] B. S. Cook and A. Shamim, "Inkjet printing of novel wideband and high gain antennas on low-cost paper substrate," IEEE Transactions on Antennas and Propagation, vol. 60, no. 9, pp. 4148-4156, September 2012.

[2] G. Shaker, S. Safavi-Naeini, N. Sangary, and M. M. Tentzeris, "Inkjet printing of ultrawideband antennas on paper-based substrates," IEEE Antennas and Wireless Propagation Letters, vol. 10, pp. 111-114, 2011.

[3] A. R. Maza, B. Cook, G. Jabbour, and A. Shamim, "Paper-based inkjetprinted ultra-wideband fractal antennas," IET Microwaves, Antennas \& Propagation, vol. 6, no. 12, p. 1366-1373, April 2012.

[4] H. R. Khaleel, "Design and fabrication of compact inkjet printed antennas for integration within flexible and wearable electronics," IEEE Transactions on Components, Packaging and Manufacturing Technology, vol. 4, no. 10, pp. 1722-1728, October 2014.

[5] FCC, "Revision of part 15 of the commission's rules regarding ultrawideband transmission systems," First Note and Order Federal Communications Commission, pp. 98-153, February 2002.

[6] DuPont ${ }^{\mathrm{TM}} \quad$ Kapton ${ }^{\circledR}$ Datasheet [Online] Available: http://www.dupont.com/

[7] H. R. Khaleel, H. M. Al-Rizzo, D. G. Rucker, and S. Mohan, "A compact polyimide-based UWB antenna for flexible electronics," IEEE Antennas and Wireless Propagation Letters, vol. 11, pp. 564-567, 2012.

[8] Novacentrix Silver Nanoparticle Ink Datasheet [Online] Available: http://www.novacentrix.com/products/metalon-inks/silver/

[9] Fujifilm ${ }^{\mathrm{TM}}$ Dimatix Materials Printer DMP-3000 [Online] Available: http://www.fujifilmusa.com/shared/bin/PDS00086-DMP3000.pdf 